\title{
sciendo MODIFICATION OF 316L STEEL SURFACE IN OZONE ATMOSPHERE
}

DOI 10.2478/ntpe-2018-0088

\author{
dr inż. Mariusz Kłonica \\ prof. dr hab. inż. Józef Kuczmaszewski \\ Lublin University of Technology, Poland
}

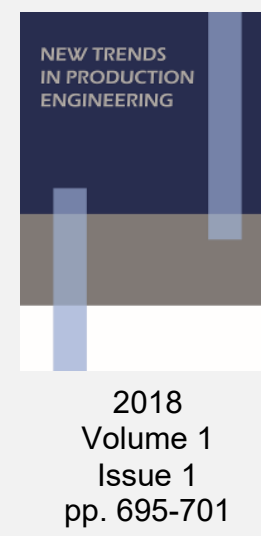

\begin{abstract}
The study reported in this paper was undertaken to assess whether certain ecologicallydisastrous surface treatments, such as chemical and electrochemical treatment could be replaced with ozonation. The proposed technology is both ecologically-sound and relatively inexpensive. The research works were conducted on $316 \mathrm{~L}$ steel substrates and involved photoelectron spectroscopy (XPS). The band positions on the review spectrum provide the basis for the qualitative identification of the atoms forming the surface layer, whereas their intensity - data for the calculation of the total concentration of these atoms in the analysed layer. High resolution spectra are used to determine the type of chemical bonds - based on the characteristic numbers of chemical shift. The results of tests on the state of surface layer energy of $316 \mathrm{~L}$ steel substrate following ozone treatment are also presented. The conducted tests and the analysis of the obtained results indicate that ozone treatment effectively removes atmospheric carbon contaminants off the specimen surface. The test results show a decrease in atmospheric carbon on samples after ozone treatment compared to untreated samples. Moreover, results show an increase in the value of the free surface energy in specimens subjected to ozone treatment.
\end{abstract}

Keywords: $316 \mathrm{~L}$ surface layer, ozone treatment, free surface energy, 316L steel

\section{INTRODUCTION}

Properly prepared surface layer of modern construction materials for industrial applications is particularly important in technologies that employ adhesion (Kłonica, 2018). Surface layer preparation methods currently used in the industry are largely based on acid or alkaline baths, which negatively affects the condition of the natural environment. These are the chemical waste products of surface layer of $316 \mathrm{~L}$ steel modification that constitute the most serious problem. Modern manufacturing requires the use of innovative solutions throughout the entire product development process: from the designing stage to the manufacturing technology itself, with particular emphasis on environmental protection (Kłonica, 2015).

Chemical (Domingues et al., 2003) and electrochemical methods (Johnsen et al., 2004) of the surface layer modification of construction materials with chemical compounds are effective in cases where it is necessary to remove contaminants strongly bound to the surface. They enable effective surface development and ensure high physicochemical activity of the surface. They also provide protection against corrosion and excessive degradation of the surface layer as a result of oxidation. Chemical treatment typically consists in etching substrates in acid or alkaline baths.

The search for alternative and effective ways of shaping energy properties (Packham, 2003) of $316 \mathrm{~L}$ steel is a vital problem from the scientific and practical points of view.

The authors of works (Koo et al., 2009), (Mahfoudh et al., 2010), (Nie et al., 1999) have shown oxidative, bactericidal and cleaning properties of ozone. In addition, the results from their studies indicate a significant effect of ozone on the wettability of the tested surfaces. The reported increase in the value of the free surface energy of the studied materials is explained as the effect of conversion of the hydrophobic surface into the surface with hydrophilic groups (Wang et al., 2005) (Xu et al., 2003). The XPS and FT-IR investigations showed the presence of an oxidised layer after ozone treatment and the effect of ozone on polar bonds such as $\mathrm{C}-\mathrm{O}$ or $\mathrm{C}=\mathrm{O}$. 
Another study (Liu et al., 2011) presented the results of research on improving the wettability of collagen scaffolds used in medicine after subjecting to ozone treatment in the modification of the surface layer. They obtained a $48 \%$ decrease in the contact angle of water of the tested material from $80^{\circ}$ to $42^{\circ}$. The XPS investigations showed the existence of many functional groups after ozone treatment, including for energy $284.9 \mathrm{eV}$ groups associated with carbon and hydrogen atoms (C- $(\mathrm{C}, \mathrm{H})$, at $286.7 \mathrm{eV}$ functional group (C-O), at 285 , EV group containing a single carbon-nitrogen bond $(\mathrm{C}-\mathrm{N})$ and an amide bond group $(\mathrm{O}=\mathrm{C}-\mathrm{N})$ for energy $287.8 \mathrm{eV}$.

The authors of the work (Fisher et al., 2006) employed ozone to obtain titanium oxide. The presented test results demonstrated the suitability of this method to obtain a surface layer of desired properties.

In their work (Linderbäck et al., 2010) the authors presented the results from tests confirming the efficiency of ozone treatment as a method of modifying the surface layer of substrates with titanium content. Ozone treatment was shown to impart hydrophilic properties to the surface, and in addition lead to the significant decrease in the value of the contact angle. XPS tests showed irreversible changes in the substrate surface layer affected by ozone. The decrease in the surface carbon content was another result of the ozone cleaning effect, whereas the increase in the oxygen content in the surface layer indicated the formation of oxides, and simultaneous decrease of pure titanium content.

\section{METHODOLOGY OF RESEARCH}

$25 \times 100 \times 1.5 \mathrm{~mm} 316 \mathrm{~L}$ steel specimens were prepared according to ASTM A480. It is acid resistant steel, thanks to the addition of Mo it has a much higher resistance to corrosion, especially in the form of corrosion pits.

Prior to contact angle measurement, the surface was treated with a P320 grit tool (abrasive paper) and degreased with a Loctite 7061 degreasing agent. The abrasive tool employed for mechanical treatment was a Hilti WFO 280 grinder.

The surface layer ozone atmosphere modification set-up for the analysed substrate material is shown in Figure 1.

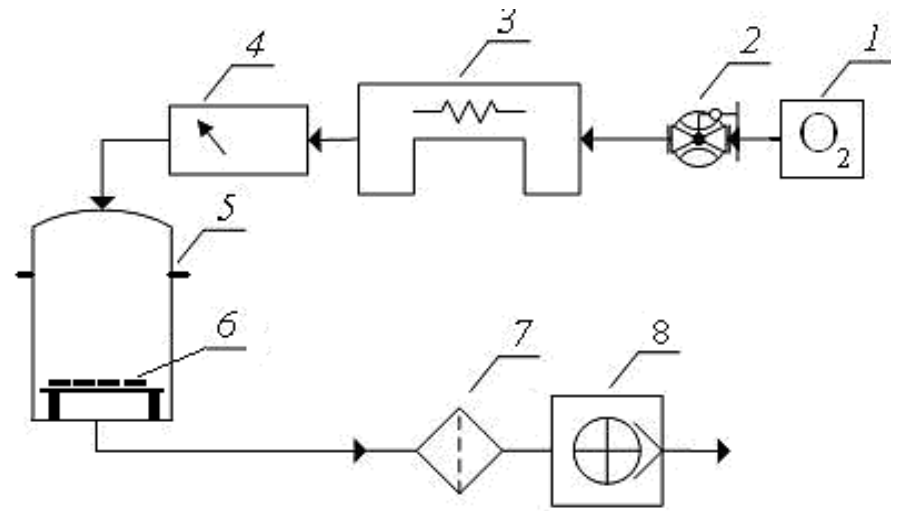

Fig. 1 Schematic of the ozone treatment set-up:

1- oxygen concentrator, 2 - flow meter with regulation, 3 - ozone generator, 4 - ozone concentration meter, 5 - reaction chamber, 6 - specimen subjected to surface layer modification, 7 - ozone destructor, 8 - suction pump

Ozone flow during the process of ozone treatment of samples was $0.9 \mathrm{dm}^{3} / \mathrm{min}$, and Ozone ANALYZER BMT 964 ozone meter was used to measure ozone concentrations. The tests were conducted in the following conditions:

No. 1- specimen after mechanical and prior to ozone treatment,

No. 2- specimen after mechanical and ozone treatment: $20 \mathrm{~g} \mathrm{O}_{3} / \mathrm{m}^{3}$ over 10 minutes,

No. 3- specimen after mechanical and ozone treatment: $20 \mathrm{~g} \mathrm{O}_{3} / \mathrm{m}^{3}$ over 30 minutes,

No. 4- specimen after mechanical and ozone treatment: $50 \mathrm{~g} \mathrm{O}_{3} / \mathrm{m}^{3}$ over 30 minutes,

No. 5- specimen after mechanical and ozone treatment: $50 \mathrm{~g} \mathrm{O}_{3} / \mathrm{m}^{3}$ over 45 minutes. 
Photographs of the surface of the tested samples were made using the Nikon MA200 optical metallurgy microscope. Photographs were recorded using the reflection technique in the bright field microscopy (BF) and the differential interference contrast (DIC). Surface microgeometry was analysed using the optical profilometry method by means of Contour GT-K1 optical profilometer and also XPS photoelectron spectroscopy. The value of the free surface energy was estimated based on the contact angle measurements. Distilled water and diiodomethane were used as measuring liquids in the contact angle measurement. A constant volume of $4 \mu \mathrm{l}$ was automatically applied to the test surface by the PGX goniometer mechanism.

\section{RESULTS AND DISCUSSION}

Fig. 2 shows photographs of $316 \mathrm{~L}$ steel. The dark areas in the centre of the image (a) are the result of ionic polishing carried out to remove surface contaminants.

a)
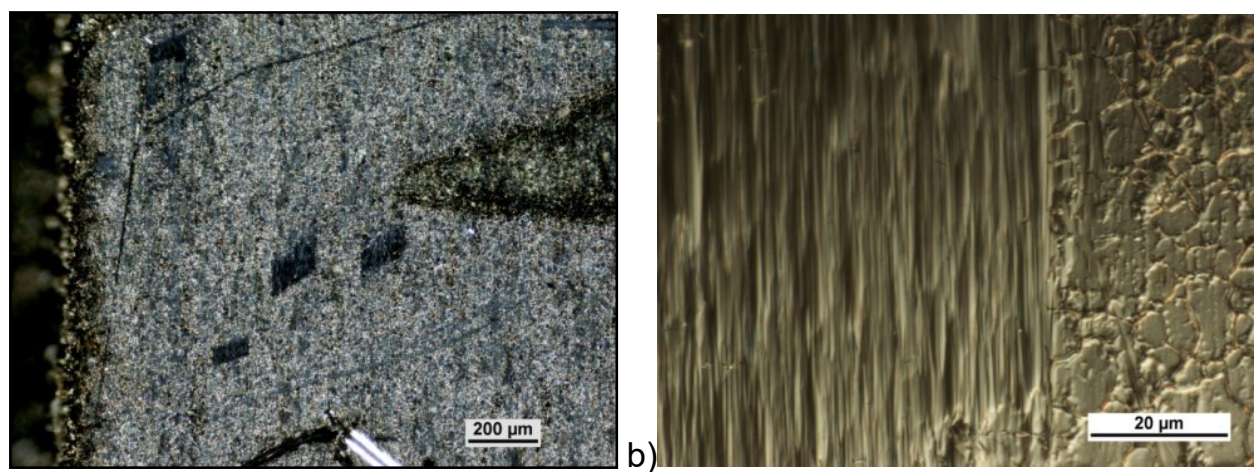

Fig. 2 Surface of 316L steel substrate: a) under polarised light at 50x magnification, b) DIC image at $1000 x$ magnification

After ion polishing, the surface was subjected to the modification of the surface layer in ozone atmosphere. Fig. $2 \mathrm{~b}$ shows the DIC image of the fragment of the specimen on the steel surface at a magnification of $1000 x$. The photo shows a clear border of the area after ionic etching.

Fig. 3 shows the topography of $316 \mathrm{~L}$ steel specimens prior to and following the modification of the surface layer in ozone atmosphere. A clear boundary was noted following ion treatment. The size of the scanned surface is $156 \times 117 \mu \mathrm{m}$.

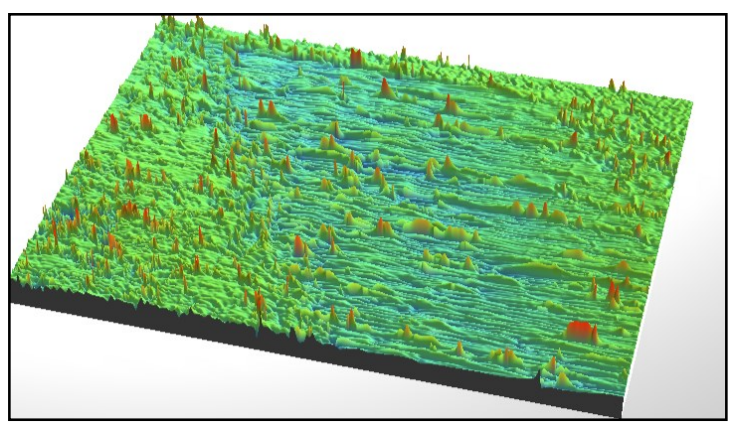

\begin{tabular}{|l|l|l|}
\hline Parameter & Value & Unit \\
\hline Sa & 0.233 & {$[\mu \mathrm{m}]$} \\
\hline $\mathrm{Sp}$ & 2.561 & {$[\mu \mathrm{m}]$} \\
\hline $\mathrm{Sq}$ & 0.295 & {$[\mu \mathrm{m}]$} \\
\hline $\mathrm{Sv}$ & -2.275 & {$[\mu \mathrm{m}]$} \\
\hline $\mathrm{Sz}$ & 4.836 & {$[\mu \mathrm{m}]$} \\
\hline
\end{tabular}

a)

Fig. 3 Surface topography and selected surface roughness parameters of $316 \mathrm{~L}$ specimens: a) prior to ozone treatment, b) following ozone treatment

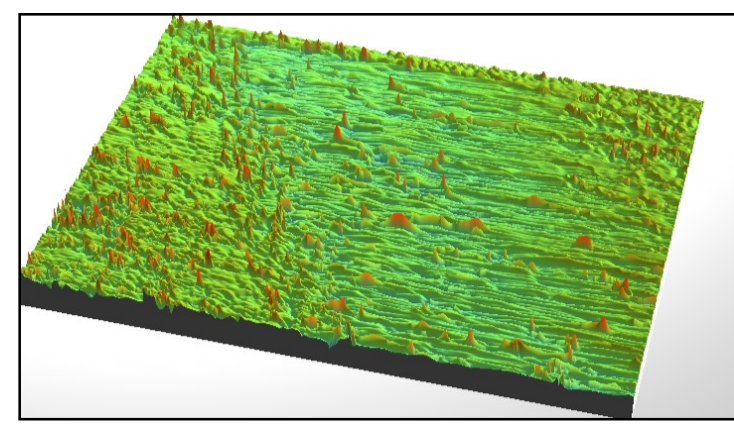

\begin{tabular}{|l|l|l|}
\hline Parameter & Value & Unit \\
\hline Sa & 0.26 & {$[\mu \mathrm{m}]$} \\
\hline $\mathrm{Sp}$ & 2.561 & {$[\mu \mathrm{m}]$} \\
\hline $\mathrm{Sq}$ & 0.33 & {$[\mu \mathrm{m}]$} \\
\hline $\mathrm{Sv}$ & -3.201 & {$[\mu \mathrm{m}]$} \\
\hline $\mathrm{Sz}$ & 5.762 & {$[\mu \mathrm{m}]$} \\
\hline
\end{tabular}

roughness parameters of $316 \mathrm{~L}$ specimens:

following ozone treatment

The pictures show the same surface area of the specimen treated by means of Focus on Ion Beam (FIB) method. The measurements show a $12 \%$ increase in the roughness of the entire 
area after ozone treatment. The observed increase in the surface roughness parameter $\mathrm{Sq}$ is from $0.295 \mu \mathrm{m}$ to $0.330 \mu \mathrm{m}$ after the ozone treatment. Other parameters similarly exhibit an increase in value following ozone treatment in relation to the untreated samples. The parameter Sp, specifying the height of the highest peak within the defined 3D profile, remained unchanged. In practice, the increase in the mean square value of the 3D profile means the deepening of the surface in the nanometric scale, which is beneficial from the point of view of this study. Clearly visible in the images are changes caused by the ozone treatment process. The analysed surfaces are characterised by a "spiky" morphology.

Fig. 4 shows a set of XPS broadband spectra recorded for a $316 \mathrm{~L}$ steel sample. In addition to the more or less intense spectral bands characteristic of the main components of $316 \mathrm{~L}$ steel, weak spectral bands of manganese and molybdenum atoms are also visible in the XPS spectra. Regarding the condition of the surface of untreated $316 \mathrm{~L}$ steel specimens and following ozone treatment, the images show surface contamination in the form of fluorine, sodium, calcium, carbon and nitrogen atoms. After ion cleaning, argon ions remain on the surface of $316 \mathrm{~L}$ steel.

The regions of the spectrum for which high-resolution XPS analysis was performed are shown in blue. In the high-energy part of the XPS spectrum there are broad oxygen KLL (EB $980 \mathrm{eV}$ ) and chromium LMM Auger electron spectra (EB 970eV), as well as iron (EB $780 \mathrm{eV})$ and nickel $(\mathrm{EB} \sim 640 \mathrm{eV})$. In all cases, the intensity axis is normalised.

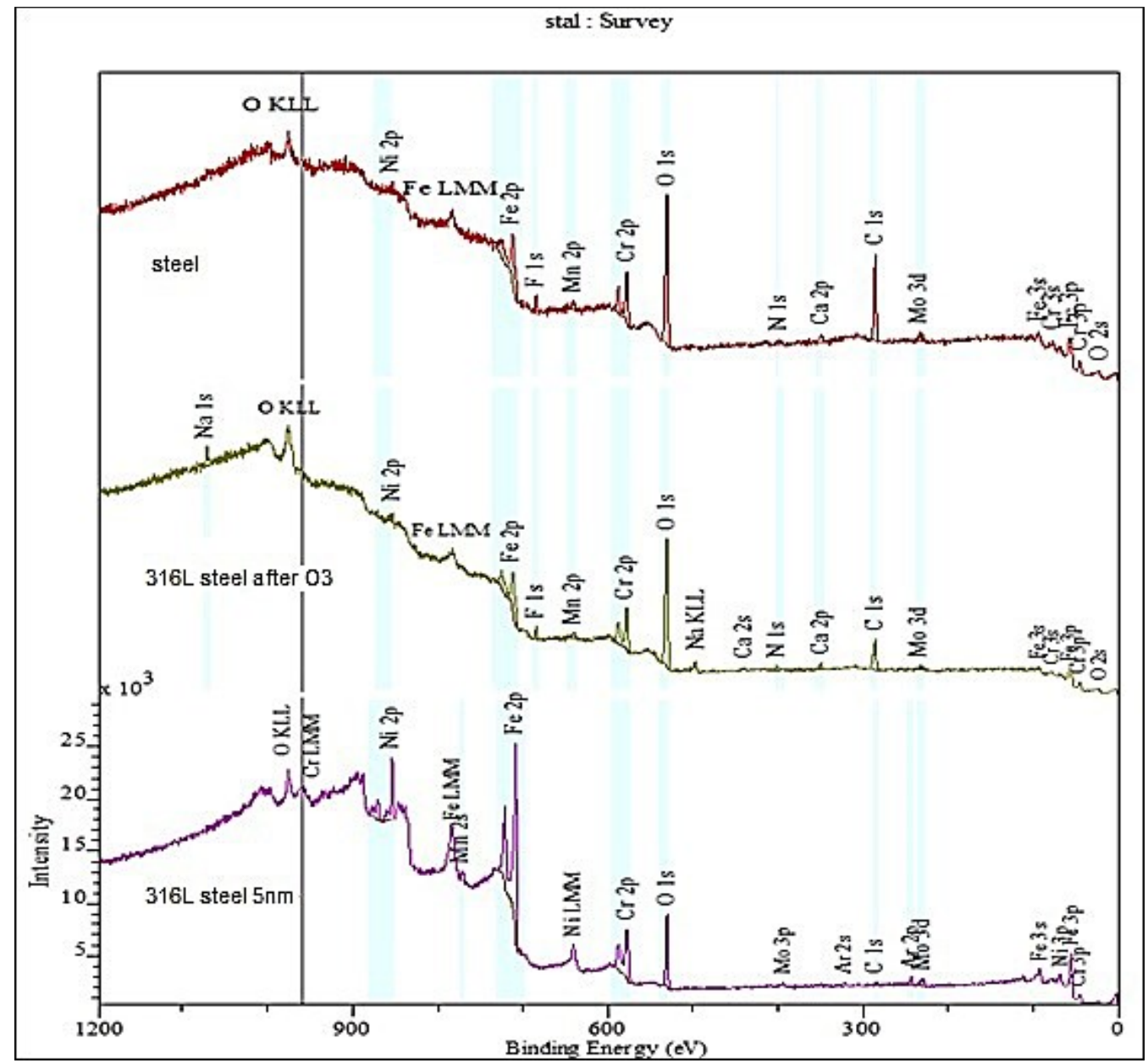

Fig. 4 A set of XPS broadband spectra of $316 \mathrm{~L}$ steel specimen, showing respectively: untreated (steel), following ozone treatment (316 L steel after O3) following plasma treatment $(316 \mathrm{~L}$ steel $5 \mathrm{~nm})$

The deconvolution of the XPS spectrum of the O1s band is shown in Fig. 5.

Spectral band profiles confirm the increase in the oxidation state of the $316 \mathrm{~L}$ steel surface after ozone treatment. The analysis of obtained results indicates the surface of untreated samples is 
covered with a layer of surface carbon, which accounts for over $48 \%$ of the total number of residing atoms. The steel surface is also largely passivated (oxidised), and the ratio of the number of metal atoms to iron ions is: $\mathrm{Fe}(0): \mathrm{Fe}(\mathrm{II}): \mathrm{Fe}(\mathrm{III}) \approx 2: 1: 2.5$. In the case of chromium, the $\operatorname{Cr}(0): \operatorname{Cr}(I I I)$ ratio is equal to $1: 6.5$. What this implies is that in contact with atmospheric air, surface chromium atoms become more easily oxidised than iron atoms. After treatment as a result of oxidation processes, there is a clear loss of carbon atoms and an increase in the concentration of metal oxides, mainly iron. What also changes is the atomic ratio $\mathrm{Fe}(0)$ : $\mathrm{Fe}(\mathrm{II})$ : $\mathrm{Fe}(\mathrm{III}) \approx 1.5: 1: 3$, from which it follows that further oxidation takes place mainly at the expense of metal atoms. Nickel is resistant to oxidation - more than $80 \%$ retains its metallic form despite ozone treatment.

After cleaning the steel surface with argon ions - by the removal of a $5 \mathrm{~nm}$-thick layer - the concentration of surface carbon atoms decreases dramatically (about 30 times) to the level of $1.17 \%$ At. The concentration of oxygen atoms also decreases (by over $20 \%$ ). As a result of ionic etching, surface contaminants and metal oxide layers are removed. This leads to the exposure of deeper layers of the metallic alloy, especially iron and chromium, and a significant decrease in the relative share of oxidised forms of metals. After cleaning the surface of the alloy, the ratio of the respective phases of iron and chromium is respectively: $\mathrm{Fe}(0)$ : $\mathrm{Fe}(\mathrm{II})$ : $\mathrm{Fe}(\mathrm{III}) \approx 6: 1: 1$ and $\operatorname{Cr}(0): \operatorname{Cr}(\mathrm{III}) \approx 1: 2$.

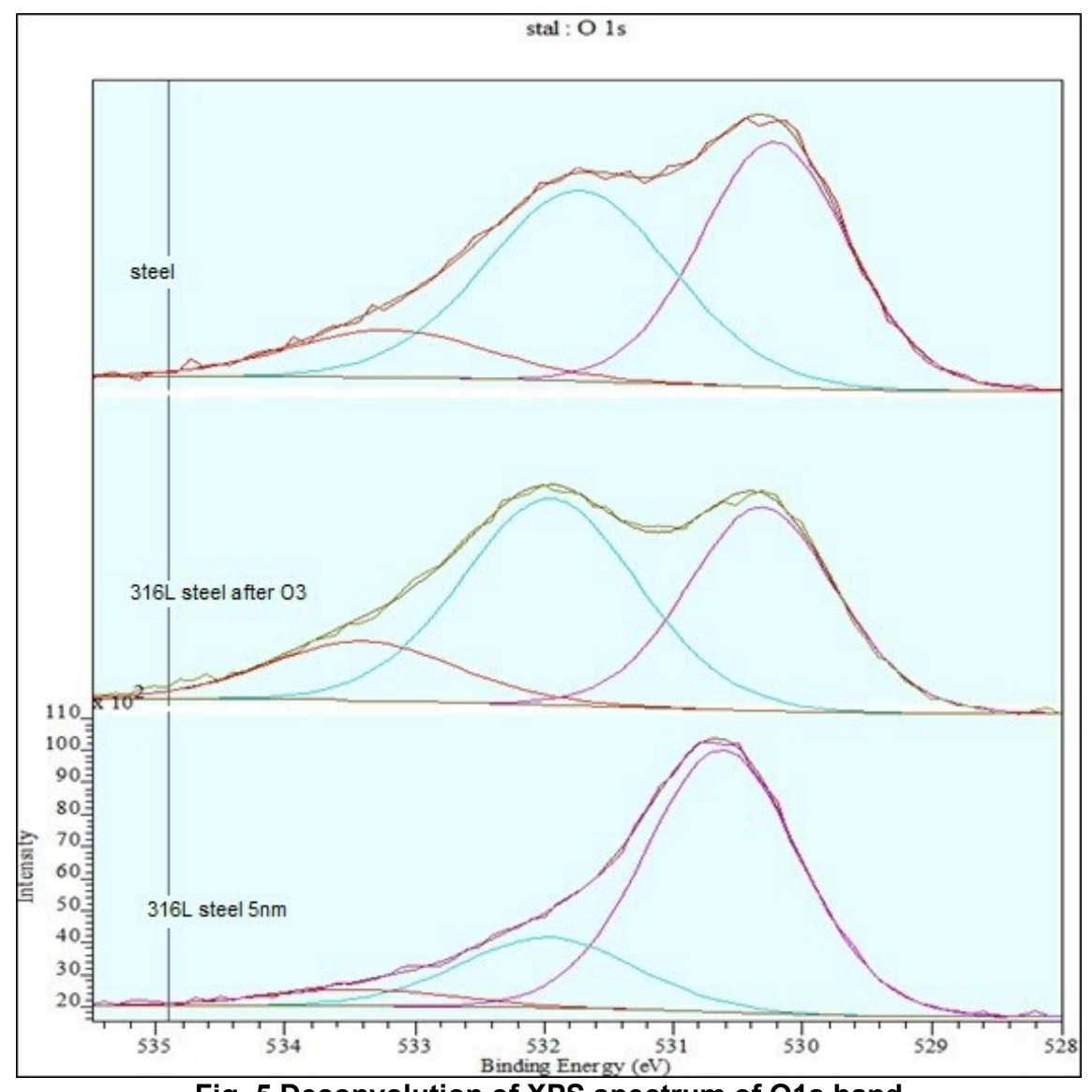

Fig. 5 Deconvolution of XPS spectrum of O1s band

The obtained results show that in the surface layer of the sample before ozone treatment, almost $64 \%$ of the total amount of iron is in the oxidised form, of which the biggest proportion $(45 \%)$ is at the highest, oxidation stage III. After ozone treatment we observe an increase in the oxidation of iron, by another $10 \%$.

A detailed analysis of the changes in the composition of the surface layer of specimens after ozone treatment in relation to the untreated samples, it can be seen that the concentration of metallic iron decreases by more than $23 \%$, which in turn allows for the increase in the amount of iron oxides, especially $\mathrm{Fe}_{2} \mathrm{O}_{3}$. This means that ozone treatment causes further oxidation of 
steel and a gradual increase in the concentration of iron ions at the maximum oxidation level, at the expense of metal atoms and iron ions II, which are less stable due to unfavourable electron configuration.

Fig. 6 shows the surface free energy of 316L steel following different surface layer treatments.

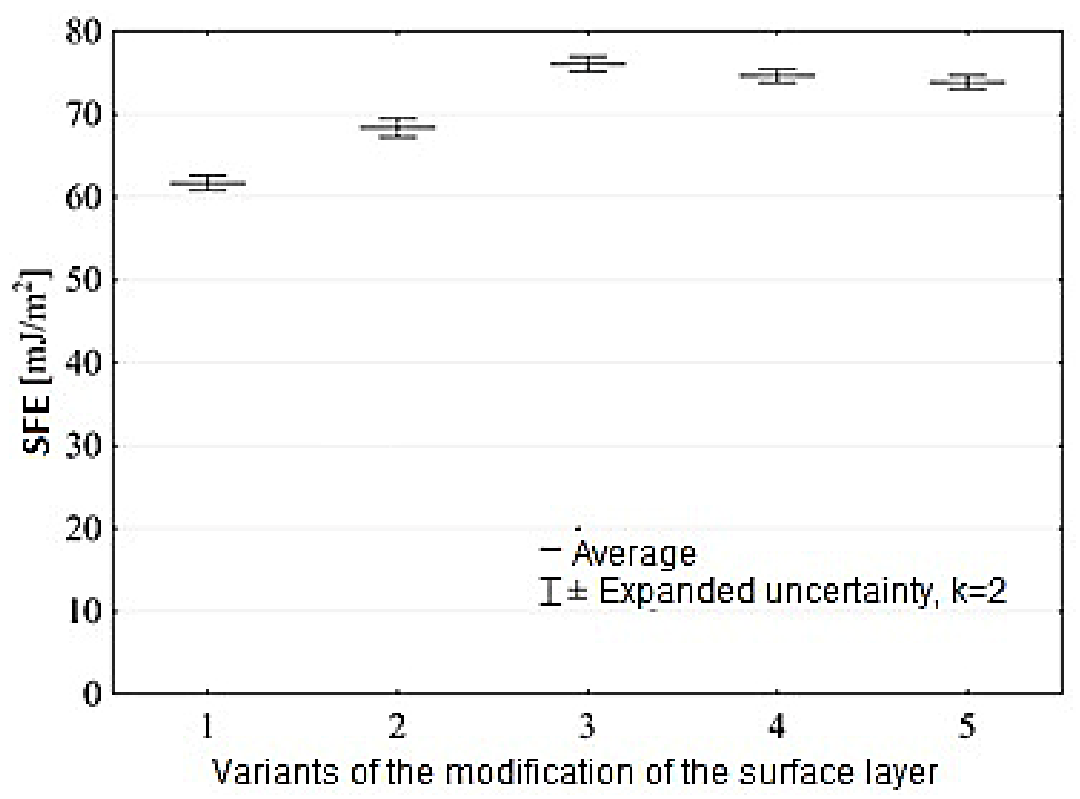

Fig. 6 Surface free energy of 316L steel after modification in ozone atmosphere

The conducted tests have provided relevant data that shows an increase in the value of the surface free energy as a result of the ozone treatment process. The highest increase in the surface free energy was observed for specimens subjected to the third variant of surface treatment, i.e. a $23 \%$ increase in relation to the specimens prior to ozone treatment. The smallest increase was noted for the second variant, which amounted to approximately $11 \%$. For the analyzed data, the maximum standard deviation value was $1.74\left[\mathrm{~mJ} / \mathrm{m}^{2}\right]$.

\section{CONCLUSION}

Based on the results from the experimental tests carried out in the presented study as well as their analysis and interpretation, it can be concluded that ozone treatment, carried out with appropriate parameters, may constitute an effective, ecologically-sound method for the modification of the energy properties of the surface layer of $316 \mathrm{~L}$ steel substrates. The effects of ozone treatment are predominantly observed as the cleaning effect and in the modification of the oxidation state of selected specimens, as well as surface roughness modification in the nano-scale. XPS photoelectron spectroscopy showed that the surface of the untreated $316 \mathrm{~L}$ steel specimens is covered with a layer of surface carbon, whose share is more than $48 \%$ of the total number of atoms in the surface layer. Following ozone treatment, as a result of oxidation, there is a clear loss of carbon atoms and an increase in the concentration of metal oxides, mainly iron. The analyses show that on the surface of the sample before ozone treatment, almost $64 \%$ of the total amount of iron is in oxidised form, of which the major portion $(45 \%)$ is at the highest, third oxidation stage. After ozone treatment we may observe an increase in the oxidation of iron by another $10 \%$.

From the perspective of adhesion processes the greatest importance of ozone treatment presented in this paper was the increase in the value of the surface free energy, which amounted to $23 \%$ compared to the specimens that were not subjected to ozone treatment.

\section{REFERENCES}

Domingues, L., Fernandes, J.C.S., Da Cunha Belo, M., Ferreira, M.G.S., Guerra-Rosa, L. (2003). Anodising of Al 2024-T3 in a Modified Sulphuric Acid/Boric Acid Bath for Aeronautical Applications. Corrosion Science, 45, pp. 149-160. 
Fisher, P., Maksimov, O., Du H., Heydemann, V. D., Skowronski, M., Salvador, P. A. (2006). Growth, Structure, and Morphology of TiO2 Films Deposited by Molecular Beam Epitaxy in Pure Ozone Ambients. Microelectronics Journal, 37, pp. 1493-1497.

Johnsen, B.B., Lapique, F., Bjørgum, A. (2004). The Durability of Bonded Aluminium Joints: A Comparison of $A C$ and $D C$ Anodizing Pretreatments. International Journal of Adhesion and Adhesives, 24, pp. 153-161.

Kłonica, M. (2015). Impact of Thermal Fatigue on Young's Modulus of Epoxy Adhesives. Advances in Science and Technology Research Journal, 9, pp. 103-106.

Kłonica, M. (2018). Analysis of the Effect of Selected Factors on the Strength of Adhesive Joints. In: IOP Conference Series: Materials Science and Engineering, 393, 012041. Available at: http://iopscience.iop.org/article/10.1088/1757-899X/393/1/012041/pdf [Accessed 03 September 2018].

Koo, J. B., Kang, S. Y., You, I. K., Suh, K. S. (2009). Effect of UV/Ozone Treatment on Hysteresis of Pentacene Thin-Film Transistor With Polymer Gate Dielectric. Solid-State Electronics, 53, pp. 621-625.

Linderbäck, P., Harmankaya, N., Askendal, A., Areva, S., Lausmaa, J., Tengvall, P. (2010). The Effect of Heat- or Ultra Violet Ozone-treatment of Titanium on Complement Deposition From Human Blood Plasma. Biomaterials, 31, pp. 4795-4801.

Liu, C., Shen, S. Z., Han, Z. (2011). Surface Wettability and Chemistry of Ozone Perfusion Processed Porous Collagen Scaffold. Journal of Bionic Engineering, 8, pp. 223-233.

Mahfoudh, A., Barbeau, J., Moisan, M., Leduc, A., Se'guin, J. (2010). Biocidal Action of Ozone-treated Polystyrene Surfaces on Vegetative and Sporulated Bacteria. Applied Surface Science, 256, pp. 3063-3072.

Nie, H. -Y., Walzak, M.J., Berno, B., Mclntyre, N. S. (1999). Atomic Force Microscopy Study of Polypropylene Surfaces Treated by UV and Ozone Exposure: Modification of Morphology and Adhesion Force. Applied Surface Science, pp. 627-632.

Packham, D. E. (2003). Surface Energy, Surface Topography and Adhesion. International Journal of Adhesion and Adhesives, 23, pp. 437-448.

Wang, M.J., Chang, Y.I., Poncin-Epaillard, F. (2005). Acid and Basic Functionalities of Nitrogen and Carbon Dioxide Plasma-treated Polystyrene. Surface and Interface Analysis, 37, pp. 348-355.

Xu, J., Yuan, Y., Shan, B., Shen, J., Lin, S. (2003). Ozone-induced Grafting Phosphorylcholine Polymer Onto Silicone Film Grafting 2-methacryloyloxyethyl Phosphorylcholine onto Silicone Film to Improve Hemocompatibility. Colloids and Surfaces B: Biointerfaces, 30, pp. 215-223. 